\title{
Court Operations during the COVID-19 Pandemic
}

\author{
Julie Marie Baldwin ${ }^{1}$ • John M. Eassey ${ }^{1}$ - Erika J. Brooke ${ }^{2}$ \\ Received: 30 June 2020 / Accepted: 1 July 2020 / \\ Published online: 12 July 2020 \\ (C) Southern Criminal Justice Association 2020
}

\begin{abstract}
This paper reviews the distinct nature of the COVID-19 pandemic and examines the resultant court responses and recommendations disseminated by various entities that support courts. Specifically, we contextualize the current environment the present pandemic has created by considering how it compares to the most-recent previous pandemics. We then review guidelines disseminated to the courts and the modifications and innovations implemented by the courts in response to the COVID-19 pandemic. Additional challenges related to these recommendations and modifications are identified and discussed.
\end{abstract}

Keywords COVID-19 $\cdot$ Pandemic $\cdot$ Courts $\cdot$ Continuing operations $\cdot$ Operational continuity

\section{Introduction}

In only a few short months, the COVID-19 pandemic has caused vast disruption across the entirety of the criminal justice. As described throughout this special issue of the American Journal of Criminal Justice, it is apparent that criminal justice agencies now face considerable unforeseen challenges - many of which they are not adequately prepared to address - while they attempt to maintain the availability and continuity of services. As a result, the overall response might be best described as one of haphazard variety as agencies attempt to balance their own needs, operations, and available resources with new directives from federal, state, and local authorities in order to control the impact of infection.

This article focuses on the challenges to court operations posed by the COVID-19 pandemic. While some of these challenges are congruent with those endured by the other criminal justice institutions (e.g., maintaining the health of both employees and

Julie Marie Baldwin

jbaldwin@american.edu

1 American University, Washington, DC, USA

2 University of Florida, Gainesville, FL, USA 
participants), courts face many of their own unique challenges as well. With this in mind, we first conceptualize and contextualize the threat posed by the COVID-19 pandemic by considering how it compares to the most-recent previous pandemics. Next, we review the guidelines and recommendations disseminated by various agencies that support courts and the modifications and innovations implemented by the courts in response to the present pandemic. We also identify additional challenges related to these recommendations and modifications. Finally, we discuss potential long-term effects on court operations in the post-pandemic era.

\section{Pandemics and Preparedness}

Compared to the types of issues and challenges that social institutions typically encounter, such as those relating to budgets, staff, or resources, a pandemic is an existential threat more akin to a natural disaster or global warming (Frailing \& Harper, 2017; Lynch, 2016). As such, it might be useful to review the conceptualization of disaster events in order to better understand how courts are addressing the challenge of COVID-19.

Killian (2002) explains that disaster events appear to progress through four quasidistinct phases of warning, impact, emergency, and recovery. These phases correspond loosely to before, during, and after the event. Unlike disasters that occur as a single discrete event, such as a hurricane, explosion, or technological failure, a pandemic is a prolonged event without clear demarcation between beginning and end. Further, as Brown (2012) notes, the impact and consequences of a disaster event are not disturbed uniformly across affected populations. Vulnerability and the ability to cope with disaster are functions of available resources and existing inequalities. In this sense, such events primarily reveal and potentially exacerbate inequalities that exist prior to disaster as inadequacies become even more unequal post-disaster.

There are two notable insights these observations provide. First, we should expect the strategic response being employed by each state or jurisdiction to evolve as the pandemic progresses and better, more accurate information becomes available. Without such information, it is difficult to develop and execute effective plans of action. This strategic evolution will likely continue to occur until such a time that it has been deemed safe to resume business as usual. Second, some courts are expected to be better able to adapt, remain in operation, or otherwise continue to deliver services compared to others based on the available resource they have at their disposal. ${ }^{1}$ These insights should be kept in mind as we review the methods by which courts are coping with current challenges.

Although this conceptualization of disaster suggests a degree of unexpected randomness associated with the timing and impact, this is not to say that courts or other institutions are expected to be unprepared to deal with such circumstances. Since the early 2000s, following the threats posed by SARS and avian flu, the Department of Health of Human Services has, in collaboration with other governmental agencies later

\footnotetext{
${ }^{1}$ It is also important to make the distinction between being able to adapt in certain ways and the willingness to do so. There are a number of factors which may contribute to how a court chooses to adapt to the current crisis, such as local culture and administrative priorities.
} 
including the National Security Council, developed comprehensive pandemic preparedness plans to prevent and control potential future influenza outbreaks (Centers for Disease Control and Prevention [CDC], 2017). As part of a national security approach, local law enforcement agencies play an essential role in these plans (Richards et al., 2006). ${ }^{2}$

The next major global pandemic of H1N1 (colloquially referred to as "swine flu") occurred from 2009 to 2010 . Correctional institutions across the U.S. were instructed to respond to H1N1 in much the same way they are responding now to COVID-19 (e.g., limiting/canceling visitation, quarantining and isolating symptomatic prisoners). Law enforcement agencies at the local level were instructed to plan and take precautions as necessary should an outbreak of H1N1 occur within their jurisdiction. Further, some courts developed or were instructed to develop strategies, consistent with the law, that included: (1) methods of social distancing to eliminate unnecessary face-to-face contact, (2) advanced sanitation procedures, and (3) the use of technology, electronic communications and documents, and electronic means of conducting court operations (Supreme Court of Florida, 2009).

In retrospect, the manner in which the H1N1 pandemic was handled is generally considered a relative success though not without its flaws (United States Department of Health and Human Services, 2012), and serves as the jumping off point for many advances in monitoring and responding to the threat of similar incidents (CDC, 2019). The Center for Disease Control indicates that much of this success was attributable to the fact that they were able to quickly communicate consistent, accurate, and scientifically-sound information to partners, policy makers, local stakeholders, and the community as it became available (CDC, 2010), which allowed all parties involved to make the best strategic decisions possible. When it comes to organizational decision making and coordinating disaster respond, the importance of such information cannot be overstated (Comfort, Ko, \& Zagorecki, 2004).

While there are indeed parallels between the previous pandemic and the current one, there are also important differences that make developing and executing an effective response challenging. The first difference has to do with properties of the virus itself. ${ }^{3}$ Compared to COVID-19, H1N1 was relatively less contagious and thus spread more slowly. The possibility of medical services being overwhelmed was therefore less of a concern. Further, its similarity to other influenza strains allowed for an FDA-approved test to become available within weeks of the first case. The ability to quickly develop a test and identify those that had been infected greatly reduced the ability of the virus to spread, again reducing the necessity of a widespread emergency response from law enforcement or the courts. Further, a vaccine became first available within months of H1N1 being declared a global pandemic.

By contrast, the COVID-19 pandemic has already had a prolonged effect globally, and a vaccine remains elusive. Importantly, a number of patients who have contacted COVID-19 remain asymptomatic, which only further complicates containment efforts and enhances its ability to spread. Combined with an incubation period of up to 14 days,

\footnotetext{
${ }^{2}$ It is important to note that there has been criticism of taking a national security approach to a pandemic compared to a public health approach (e.g., Annas, Mariner, \& Parmet, 2008).

${ }^{3}$ For a timeline of the H1N1 pandemic, see the "2009 H1N1 Pandemic Timeline" (Center for Disease Control and Prevention, 2009).
} 
its communicability has the potential to overwhelm the health care system if extensive precautions are not taken. As a result, the impact of the COVID-19 pandemic has been far reaching, negatively affecting the day-to-day operations of nearly all businesses and social institutions in the U.S., including all institutions of the criminal justice systemnot just corrections.

The second way in which COVID-19 differs from the H1N1 is the governmental response. As noted previously, the effectiveness of the H1N1 response had much to do with the way in which information was conveyed, allowing for the most informed decisions possible. By contrast, the messaging related to COVID-19 has been largely disorganized, often with conflicting statements being delivered by different government officials (Sink \& Parker, 2020; Torres, 2020). Further, statements made by the federal government appear to give the impression that COVID-19 poses minimal risk (Kaczynski, Steck, \& McDermott, 2020). Another important distinction between the two most recent pandemics is that there was a systematic, top-down response to H1N1 whereby the federal government, led by the Center for Disease Control, guided the states in their response. ${ }^{4}$

As a result, decisions made by criminal justice agencies in response to COVID-19 have been informed by directives from myriad sources, including the CDC, governors, mayors, attorneys general, state emergency management, and other non-governmental organizations. Thus, there is much variation between states and even jurisdictions in how they are adapting operations in order to cope with the challenges posed by COVID-19.

\section{Court Responses and Challenges to COVID-19}

The primary goals of effective emergency management response include maintaining both the continuity of services, especially essential services, and the health and safety of those responsible for providing those services (Florida Courts, 2020; Pretrial Services Agency, 2013). The courts have been unable to simultaneously meet general safety guidelines while maintaining full operations and usual caseloads. Consequently, the primary response among many courts has been to either reduce or eliminate their inperson practices by halting all such operations, even closing their physical locations to all but the most essential personnel (e.g., Miller, 2020, June 30). As an alternative to inperson dockets, some courts have adopted all-virtual, limited in-person, or hybrid (virtual and limited in-person) formats in an effort to maintain operational continuity, while reducing transmission, and comply with health and safety directives.

Since late March of 2020, efforts to transition to virtual environments and work remotely have been aided by various non-governmental organizations (NGOs), such as the National Association of Court Management, the National Center for State Courts,

\footnotetext{
$\overline{{ }^{4} \text { Importantly, the aforementioned }}$ plans that had been in place for more than a decade were not implemented due to vacancies among the institutional positions responsible for overseeing implementation under the current administration occurring in the months prior to the initial spread of the virus. A point of political contention was whether the members of the National Security Council Pandemic Response Team had been literally fired by the President. While it is not clear what actually occurred, the preponderance of the evidence suggests that the team was disbanded while some members resigned in 2018, but no replacements for those roles were appointed (Reuters, 2020).
} 
the Council on Criminal Justice, and the Justice Management Institute, who seek to minimize the pandemic's impact on the administration of justice. These activities have included posting online resources and conducting webinars that provide guidance to courts on best practices and strategies for implementing their operations in the current environment.

While the commitment to justice many courts have displayed is laudable, the nature and speed at which these efforts have been adopted also pose a variety of challenges to court personnel, case parties, and the general public. In this section, we synthesized the early guidance provided by various organizations and the modifications reported by courts, as well as provide additional recommendations to support operational continuity. In terms of challenges, we identified issues related to both the recommendations and the implementation of modified practices.

This section focuses on modifications related to court format and substantive operations, as well as the issues related to these modifications. Some courts that have continued in-person practices fully or in a limited capacity but have restricted the number of individuals permitted in shared space, implemented social distancing, required the use of masks, and provided disinfectant. However, these measures might be best thought of enhancements to existing practices. They do not alter how the courts actually operate, for example, how they convene, communicate, process cases, and protect private information. As such, we address substantive changes in practice that the courts have adopted for operational continuity in response to the COVID-19 pandemic, as well as the challenges that have arisen from such innovations.

\section{Moving to Virtual Processes}

As the pandemic has progressed, courts across the country at all levels have begun to utilize technology to largely reinstitute their processes, including the Supreme Court of the United States (SCOTUS) for the first time in history (Howe, 2020; Hurley \& Chung, 2020, April 13). The use of audio and video conferencing technology, in particular, has been a great resource for courts as they allow for judges, counsel, and court personnel to continue to convene and confer as necessary, albeit in a different format. Courts have had to also consider remote access to the courts for court participants, and court leaders must support virtual representation in various ways (see "Logistical Issues and Security Concerns"). While these modifications allow for courts to continue to function in certain capacities, they also inhibit public access to the court room, create new challenges for court personnel, and pose obstacles for case parties and those required to have contact with the court.

Many lower federal courts and state supreme courts have moved to holding arguments remotely. For instance, U.S. Court of Appeals for the District of Columbia Circuit (DC Circuit) "ordered that all in-person onsite oral arguments be suspended" and be postponed, proceed by teleconference, or decided without oral argument (United States Court of Appeals for the District of Columbia Circuit, 2020, March 17). While the U.S. Court of Appeals for the District of Columbia Circuit held some oral arguments via teleconference, Supreme Courts for Michigan and Texas utilized video-conferencing platforms (Howe, 2020).

Holding ordinarily-public proceedings, such as oral arguments in the SCOTUS (Howe, 2020, Hurley \& Chung, 2020, April 13), but barring public access to public 
proceedings is potentially problematic. Lack of access not only weakens public trust and confidence in the courts, but it also violates the First and Sixth Amendments. In response, several courts that have moved to conducting hearings via audio or video technology have made these available to the public by streaming them online. Taking the examples above, the DC Circuit and the Michigan and Texas Supreme Courts streamed their audio and video sessions, respectively, online for the public to observe in real time (Goldstein, 2020; Howe, 2020; Slayton et al., April 7, 2020). Additionally, a Texas court decided to stream video of their hearings live on YouTube with watermark asking viewers not to record the hearing. Once the hearing is over, it is not saved on YouTube (Slayton et al., 2020, April 27). While streaming hearings is not unheard of as many courts in Florida live streamed first appearances prior to the pandemic (Orange County Government Florida, 2020), the array of proceedings streamed virtually is notable.

Treatment courts (also known as problem-solving, specialized, or specialty courts) may be faced with additional challenges given their distinct mission and operations. Treatment courts hold frequent staffings ${ }^{5}$ and status hearings ${ }^{6}$ to facilitate enhanced supervision, treatment monitoring, a team-centric approach, and meaningful interaction between the judge and participants. Hardin and Sydow (2020, March 26) recommended for treatment courts to consider whether they can hold fewer court staffings and status hearings, suspend them altogether, or develop processes to conduct staffings and status hearings using virtual platforms (Hardin \& Sydow, 2020, March 26). Regardless of what course of action is taken, any modifications to court processes and participant requirements should be communicated to participants both verbally and in writing (Hardin \& Sydow, 2020, March 26).

While many of these modifications can support courts' continuity of operations, they also pose a variety of new challenges. For instance, rendering decisions without oral arguments does not permit for counsel to respond in real time to the judiciary's questions (e.g., United States Court of Appeals for the District of Columbia Circuit, 2020, March 17) and may produce substantively different outcomes. Postponing proceedings will create additional backlogs to an already overburdened system and may violate defendants' right to a speedy trial. Equally, holding fewer or suspending staffings and status hearings pose multiple undesirable ramifications for both the courts and participants, such as decreased oversight and participant supervision, reduced judicial interaction with participants, and increases in program length.

Moving court operations to a virtual environment can support courts' continuity of operations and can even be beneficial in some ways (e.g., eliminates transportation issues for court participants), but virtual context presents challenges for several courtspecific operations. Such operations include managing victim and offender interactions and jury selection and deliberations, which are all court elements that cannot be readily transitioned online, if at all.

Official guidance on virtual processes for court proceedings has yet to be published. Court staff and leaders have had to immediately develop and implement their own

\footnotetext{
5 Team staffings are meetings in which the treatment court team (traditional court actors, treatment providers, and other partners) gathers to discuss issues such as eligibility of potential participants, participant requirements, participant progress and supervision, termination and graduation, and sanctions and incentives.

${ }^{6}$ Status hearings are court sessions in which participants appear before the treatment court team to discuss updates and progress, including noncompliance.
} 
protocols in the wake of the pandemic, and a streamlined virtual approach has not been identified. Moving courts to a virtual platform also requires the appropriate resources for which many courts may need additional funding. As previously noted, courts have had to assess the availability of equipment and technology for essential staff to continue specific court operations. Additionally, relying solely on technology to operate the courts creates concerns for both privacy and security (see next subsection).

\section{Logistical Issues and Security Concerns}

Conducting court functions electronically presents new logistical and security issues that require creative and innovative thinking. Court leaders must consider how to facilitate representation and attorney/client meetings, provide personnel access to records off-site, ensure all parties can operate the technology and requisite equipment, confirm identities, obtain signatures, securely function in a new virtual environment. In shifting court operations to a virtual environment (partially or fully), staff have had to determine which court functions (see "Triaging Court Functions") and resources are the most vital for operations and then assess their available resources in terms of both equipment (e.g., laptops, printers) and technology to ensure that the appropriate personnel have access the requisite resources for their duties (National Association of Court Management, 2020a, April 2). Such technology may include shared drives, virtual private networks (VPNs), and electronic conferencing platforms (e.g., Zoom, WebEx).

Court leaders must help facilitate the interaction between court clients/ participants and the court on electronic or virtual platforms (National Center for State Courts, 2020a). The court must ensure that case parties and counsel can communicate and exchange documents with each other (National Center for State Courts, 2020a, 2020b). Conferencing platforms should be at no cost to court litigants (National Center for State Courts, 2020b), as well as treatment court participants. They should be easy to use, not require specialized training or equipment, and have the flexibility to be used on different devices, such as smart phones, tablets, and laptops (National Center for State Courts, 2020a, 2020b). In facilitating virtual attorney/client meetings, one court allowed for litigants to meet with their attorneys to discuss case matters via Skype (Slayton et al., 2020, April 7). Options mentioned regarding electronic document sharing include scanning and then uploading documents to an online drive or emailing them to appropriate parties (National Center for State Courts, 2020a). Courts should provide instructions ("how-to guides") to litigants and participants on how to utilize these communication platforms (National Center for State Courts, 2020a) and any signature and document software employed. They should also clearly stipulate for what purposes different platforms or software are to be used and with whom the litigant/participant should be using them, with which specified individuals or roles.

Additionally, counsel and court personnel may need to obtain signatures from court participants in real time. Signatures could be obtained through the use of software, such as Adobe Acrobat or DocuSign (National Center for State Courts, 2020, April 15). Similar to the conferencing platforms, these signature options should not require any cost from clients or participants, should be easy to use, and be able to be used across multiple types of devices. 
Moving off of a court's hard line network can also create challenges for accessing court records (National Center for State Courts, 2020a). National Center for State Courts, 2020a recommended that electronic records should also be available remotely to specific employees. Remote access could be accomplished by using a VPN and shared drive.

Confirming the identity of court participants through non-video electronic means has also been identified as a challenge (National Center for State Courts, 2020, April 15). If a defendant takes part in court proceedings where the court could not see the individual, such as through telephonic means, the defendant's attorney or another party would need to attest under oath that it is in fact the defendant on the phone (National Center for State Courts, 2020, April 15).

While the aforementioned efforts to support operational continuity are commendable, there are challenges related to these recommendations and modifications. For instance, choosing technology that can be accessed on different mediums (e.g., laptops, smart phones, tablets) does not solve accessibility issues related to resource disparities. Not all participants and court personnel may have strong Internet connections, or even Internet access, at home. Similarly, not everyone may have access to a computer, laptop, tablet, or smartphone; many courts do not have laptops available to personnel to take home to work remotely. Additionally, the development of instructional materials for the use of technology would likely fall on court personnel who may not be fully familiar with the new platforms or software. Further, access to electronic records is problematic for many courts. For courts have maintain electronic records, moving off of the court's hardline system may not be possible, meaning the records cannot be accessed outside of the office. Other courts do not have robust electronic records or even keep electronic records; many courts and counsel still maintain paper records and files that have not been digitized.

In addition to the legal and logistical issues that accompany the transition of court operations into an alternative and potentially unfamiliar format, there are a number of security and privacy concerns to consider. As suggested above, the process of partially or fully transitioning court operations to a digital format involves the integration of a number of different applications and platforms, each of which may have their own set of vulnerabilities. Even the wide utilization of technology in other industries is not a guarantee of well-engineered security. Moreover, increased visibility and market share make such technologies likely targets compared to the obscure and underused. ${ }^{7}$ For example, Adobe Acrobat, one of the most enduring applications for creating and reading PDFs, is known to have security vulnerabilities that have been exploited in the past (e.g., Gabbatt, 2013, October 3). On the other hand, it also receives frequent updates and security patches that older or otherwise abandoned projects would not receive (Sun, 2020, May 1). However, unknowingly running an older, unpatched version may still pose security concerns.

\footnotetext{
${ }^{7}$ Perhaps the best example of this was the apocryphal marketing claim from the Apple Computer Company that "Macs can't get viruses" attributable in part to the fact that the Windows operating system was a more widely available target. The rise of Apple over the last several years has demonstrated the security issues associated with being popular (The Telegraph, 2012, June 6).
} 
Along the same lines, videoconferencing platforms are potentially vulnerable to being accessed by unauthorized third parties. This includes not only malicious actors, but also the vendors themselves who may be accessing and storing the data that is being shared on their platforms, in a potentially-vulnerable manner (Hodge, 2019, December 27). For example, the web conferencing platform Zoom quickly rose to prominence when sheltering-in-place guidelines took effect but quickly gained scrutiny for its security practices as well as obfuscated connections to the Chinese government (Conklin, 2020, April 7). The nature of this relationship remains unclear, and it is not certain whether anything nefarious is occurring. Users of any web conferencing application should exercise caution when sharing sensitive information and have a clear understanding of how that platform handles and secures data. Courts should make a concerted effort to avoid using any application that does not disclose this information. More generally, users should remain cognizant when doing anything that directly interfaces with others, such as screen sharing during a video-conference or webinar, so as not to accidently display information that should remain secure.

The popularity of certain platforms, such as Skype and Zoom, has been attributed to the facts that they are easy to use and have free, no-cost versions. Cost and ease of access are two important elements that courts consider when making purchasing decisions, which will likely continue to be high priorities as they transition to a virtual environment. Courts that have limited or set budget allocations for technological solutions are likely to find free software appealing, especially when trying to quickly pivot operations and adapt to unforeseen circumstance without additional budgetary support. However, the idea of free software may bring to mind the old adage that "if you are not paying for it, you are the product not the consumer," alluding to the extensive data harvesting in which many companies engage. While this practice no doubt occurs, it is not universally the case. Courts that have this concern might do well to consider open-source software solutions, especially those that extensively integrate encryption for security. Compared to proprietary software that utilizes source code unknown outside of the developers, open-source software is noteworthy for allowing the source code to be available and audited by others to verify security fidelity. Criminologists are potentially most familiar with open-source software in terms of the statistical software R, but there are a number of open-source solutions available, including those for video teleconferencing.

A final point of consideration is with respect to ease. When considering which software platforms to adopt, there is a delicate balance between security and usability. Sacrificing user experience for security can potentially backfire. Security protocols that are too cumbersome or overburdening for the user are prone to be circumvented or abandoned altogether. Further, it is often said that the weakest point in any security system is the end user. Many types of malware rely on the user, knowingly or unknowingly, downloading a file, installing a program, clicking a link, or inputting credentials somewhere that they should not (Jang-Jaccard \& Nepal, 2014). Along these same lines, social engineering tactics utilize psychological manipulation or deception to trick users into divulging secure information. "Phishing," which attempts to deceive the user (often via email) by disguising the attack as a legitimate communication from a trusted partner, is perhaps the most well-known example of this type of tactic.

While it is not possible to remove all threats, it may be possible mitigate some risk by educating and training court personnel to recognize and avoid these types of scams 
(Abawajy, 2014; He \& Zhang, 2019) and to engage in more pro-active security-focused behaviors (McCrohan, Engel, \& Harvey, 2010). Providing personnel with a separate, dedicated laptop for court activities and easy-to-understand instructions on how to secure home networks may also reduce the chance of conducting sensitive court activities on a machine already infected with malware. Lastly, our review of resources for courts transitioning to a virtual format show that most provide only a modest yet vague treatment of cyber security, if mentioned at all. Therefore, it would likely be of value for training and technical assistance providers to offer information on best practices in cyber security, so that courts may be proactive against potential threats.

In addition to the above, treatment courts have the additional challenge of protecting participant health and treatment information, which is subject to HIPAA regulations. Any solution treatment courts adopt to store, transfer, and access such information must not only be secure but also must be HIPAA compliant. While most of the large providers are able to meet these requirements, many do so in upgraded versions, separate packages, or add-ons that come at an additional cost. Treatment courts must be cognizant of whether their chosen solutions are able to meet these requirements.

\section{Triaging Court Functions: Case Prioritization, Detention, Plea Bargains, Jury Trials, Fees/Fines}

Some types of proceedings naturally transition easier to a digital environment, such as first appearance hearings, while others are more complex (e.g., jury trials and treatment court graduations). For that reason, some jurisdictions have prioritized case types (Slayton et al., 2020, April 7). The NCSC recommended that courts suspend all but the most critical case types during the pandemic (2020, March 26). Critical case examples provided include protective orders, custody and property matters, pandemic-related proceedings, and delinquency cases that protect youth (National Center for State Courts, 2020, March 26). Treatment court staff have had to make decisions to either suspend new intakes or create a virtual option for accepting clients. Hardin and Sydow (2020) explained that courts have been faced with choices on whether to suspend all new intakes and create a waitlist of referrals or develop virtual processes to accept new participants. Similarly, treatment courts are also tasked with determining whether to suspend all in-person graduation activities and termination hearings or develop alternatives to group graduation activities (Hardin \& Sydow, 2020).

There has been an increase in plea bargains during the pandemic due to COVID-19 risks and system concerns. While this can be both advantageous for the court and defendant, there is a concern that defendants may feel pressured to plead guilty to stay out of jail due to their health concerns amid the COVID-19 pandemic. As such, the court needs to have a plan in place to address defendants' claims of pleading guilty under distress during the pandemic (Council on Criminal Justice, 2020, April 7). Experts have suggested including language within the plea agreements that states that defendants are agreeing to the terms of the arrangement under their own volition and are not under distress to which they must attest to prior to signing the plea agreement (Council on Criminal Justice, 2020, April 7).

Additionally, the Council on Criminal Justice (2020, April 7) noted that some states' focus during the pandemic has been on pre-trial detention hearings as a means to reduce 
current constraints on the courts. One option has been to consider the possible sentence that an individual would receive if found guilty of the charge(s), and if it does not warrant jail time, then courts may consider pre-trial release as a way to address the charge at a later date (Council on Criminal Justice, 2020, April 7). Further, the Justice Management Institute (2020) recommended that courts create a process for the continuation of cases involving individuals in detention in an effort to help decrease the jail population.

The pandemic has also led to a temporary suspension of jury trials due to various stay-at-home orders and as a safety precaution for potential jurors. As some courts plan to resume jury trials as early as late June or July, courtroom workgroups have been formed to address communication strategies to the public about the safety of resuming jury trials, pre-assembly processes, assembly and selection of jurors, and jury deliberations (Resumption of Jury Trials Workgroup, 2020). A workgroup in Washington, the Resumption of Jury Trials Workgroup, has suggested the use of virtual vior dire processes in which potential jurors could take part in jury selection remotely (2020). They also proposed the construction of "new jury instructions to address mask-wearing, remote testimony and appearances, and open courts, in both criminal and civil contexts" (Resumption of Jury Trials Workgroup, 2020:36).

The move to virtual court operations and the negative economic impact of the pandemic have affected the collection of court fees and fines. Courts have opted to waive or suspend the collection of fines and fees during the COVID-19 pandemic. This required courts to contact the third parties responsible for collecting fines and fees to inform them of a pause in collections, and to have a contingency plan prepared to address the backlog in the post pandemic era (Justice Management Institute, 2020).

Again, while these recommendations and modifications can support continuity of some ocurt operations, they pose their own challenges. For instance, suspending the processing of certain cases in triaging could violate speedy trial rules and increase case backlogs. For defendants taking plea bargains, there is the potential that they may contest their pleas claiming they plead guilty due to distress, which is why experts have recommended including additional language to pandemic-era pleas and suggested that courts should have a plan in place to deal with this concern. However, organizations supporting court operations have not provided information on what such a plan would look like.

Suspending treatment court intakes and graduation ceremonies have their own challenges. Suspending intakes may threaten current treatment court funding, create backlogs, and deny eligible participants program entry. Graduation ceremonies not only celebrate and reward court participants for their hard work in completing the program, but they also serve as a way to increase support for the program among community, stakeholders, elected official, and the press (National Association of Drug Court Professionals, 2018), as well as other participants.

Additionally, modifications to jury trials in the pandemic era are fraught with problems. Video can be distorting and biasing, so courts must consider how lighting, framing, and camera angles may affect jurors' assessments of witnesses and defendants (McCormick \& Lufrano, 2020). In terms of remote service, there is a concern about whether jury deliberations would remain private. Additionally, not all potential jurors would have access to the required technology and resources (Internet, laptop) nor do they all have the experience with technology to participate remotely, and many courts 
do not have the resources to lend the requisite equipment. As such, one questions whether potential jurors would then be excluded due to inadequate resources or technological experience. If so, this affects defendants' rights to a jury of their peers.

\section{Reopening Courthouses}

In the midst of courts operating or attempting to operate virtually in varying degrees, court leaders must also prepare for re-opening once stay-at-home orders have been lifted and jurisdictions move to re-open. Courts have already started to plan what in-person protocols will look like once court proceedings resume in the courthouse (National Association of Court Management, 2020, April 23). For court employees, it has been proposed that the court create a screening tool that inquiries about symptoms (e.g., cough, fever), any domestic or international travel within the past 14 days, and exposure to anyone who has tested positive for COVID-19. If employees respond affirmatively to any of these questions, they should be sent home (National Association of Court Management, 2020, April 2). However, teleworking for judges and court staff is still recommended when possible; "courts should continue remote proceedings in all cases where it is possible and practical" (National Center for State Courts, 2020, May 1b:1).

It has also been recommended that court leaders consult with local public health officials to determine what additional regulations should be implemented at the time of reopening for those entering the courts. If a health screening is recommended for individuals entering the courts, it is preferred that medical professionals conduct the screening in lieu of court staff (NCSC, 2020, Mayla), and screeners should be given masks and gloves (NCSC, 2020, May 1b). Additionally, court leaders have considered reconfiguring court rooms to ensure social distancing requirements are met (NACM, 2020, April 23) and should consider how to social distance in common areas, such as hallways, elevators, restrooms, and galleries (NCSC, 2020, May 1b). Signs of new protocol need to be visible throughout the courthouse, and sanitizer dispensers should be available are various locations in the courthouse (NCSC, 2020, May 1b).

Courts must also contend with personnel and cases involving defendants or parties who have COVID-19. The courts must abide by the HIPAA laws and not publicize medical information (National Judicial College, 2020, March 19).

In reinstating grand juries and jury trials, the question arises as to whether potential jurors may opt out of service over health concerns. The self-selection of potential jurors opting out for COVID-19-related reasons could affect defendants' right to trial by impartial jury.

\section{Conclusion}

Despite the fact that the most recent pandemic was approximately a decade ago, it appears that many courts and court-specific support organizations were not prepared for a pandemic such as COVID-19. It is clear that all courts do not have the adequate resources, technology, digital record systems, and strategies of using technology to maintain operations given current events. As such, the initial 
response of many courts, including SCOTUS, was to temporarily suspend operations until alternative approaches could be developed. For many courts, this involved first identifying essential functions and then devising ways to maintain some of those functions outside of their standard practices. However, some courts have yet to resume any essential functions in the current environment given their resource limitations.

As the COVID-19 pandemic persists, the next steps for many courts will likely involve developing ways to further reinstitute functionality in novel ways. Courts that have been unable to restore even the most basic functions should continue their efforts to do so as they may run into Constitutional issues if they remain unable to resume certain operations. Thus far, some funding has been made available to assist in these efforts and will hopefully be directed to courts that remain largely suspended due to limited resources.

At the same time, the current circumstances provide unique opportunities. In order to address the challenges posed by COVID-19, courts have been forced to explore innovative ways to achieve their mission. Ordinarily, organizational inertia is such that change is often incremental while the reasons for change have a tendency to get lost or get muddied due to changes in administration, loss of key personnel, and budgetary constraints that inevitably occur over time. By contrast, the current pandemic has forced rapid changed with a clear goal, operational continuity. While it remains to be seen which adaptations will persist in the post-pandemic era, it is possible that many courts will emerge from the pandemic more efficient, resourceful, and modernized in their operations.

\section{References}

Abawajy, J. (2014). User preference of cyber security awareness delivery methods. Behaviour \& Information Technology, 33(3), 237-248.

Annas, G.J., Mariner, W.K., \& Parmet, W.E. (2008). Pandemic Preparedness: The Need for a Public Health Not a Law Enforcement/National Security - Approach. Available at: https://www.aclu. org/sites/default/files/pdfs/privacy/pemic_report.pdf

Brown, B. (2012). Disaster myth or reality: Developing a criminology of disaster. In M. Deflem (Ed.), Disasters, hazards and law (sociology of crime, law and deviance, 17) (pp. 3-18). Bingley: Emerald.

Center for Disease Control and Prevention. (2009). 2009 H1N1 Pandemic Timeline. Available at: https://www.cdc.gov/flu/pandemic-resources/2009-pandemic-timeline.html

Center for Disease Control and Prevention. (2010). The 2009 H1N1 Pandemic: Summary Highlights, April 2009-April 2010. Updated: June 16, 2010. Retrieved: April 19th, 2020 from https://www.cdc.gov/h1n1 flu/cdcresponse.htm

Centers for Disease Control and Prevention. (2017). National Pandemic Strategy. Available at: https://www. cdc.gov/flu/pandemic-resources/national-strategy/index.html

Centers for Disease Control and Prevention. (2019). Summary of Progress since 2009. Available at: https:/www.cdc.gov/flu/pandemic-resources/h1n1-summary.htm

Comfort, L. K., Ko, K., \& Zagorecki, A. (2004). Coordination in rapidly evolving disaster response systems: The role of information. American Behavioral Scientist, 48(3), 295-313.

Conklin, A. (2020, April 7). Zoom under fire for security vulnerabilities, Ties to China. Fox Business. Available at: https://www.foxbusiness.com/technology/zoom-china-ties-security

Council on Criminal Justice. (2020, April 17). Facing COVID-19 in the Courts (Webinar). Available at: https:/justiceroundtable.org/event/council-on-criminal-justice-facing-covid-19-in-the-courts/

Florida Courts. (2020). Strategy for Pandemic Influenza and Other Infections Disease Outbreaks - Keeping the Courts Open in a Pandemic: Template for Planning Tasks Associated with Preparing for a Pandemic. 
Available at: https://www.flcourts.org/content/download/607717/6891939/pandemic-appendix-templatecoop-v2.0\%2020200227.pdf

Frailing, K., \& Harper, D. W. (2017). Toward a criminology of disaster: What we know and what we need to find out. New York, NY: Springer.

Gabbatt, A. (2013, October 3). Adobe warns 2.9 million customer of data breach after cyber-attack. The Guardian. Available at: https://www.theguardian.com/technology/2013/oct/03/adobe-hacking-databreach-cyber-attack

Goldstein, T. (2020, March 15). Holding Oral Arguments During the Coronavirus Pandemic. https://www. scotusblog.com/2020/03/holding-oral-arguments-during-the-coronavirus-pandemic/

Hardin, C., \& Sydow, N. (2020, March 26). Treatment Courts and COVID-19: Pandemic Guidance (Webinar). Available at: https://vimeo.com/401116822

He, W., \& Zhang, Z. (2019). Enterprise cybersecurity training and awareness programs: Recommendations for success. Journal of Organizational Computing and Electronic Commerce, 29(4), 249-257.

Hodge, R. (2019, December 27). 2019 Data Breach Hall of Shame: These Were the Biggest Data Breaches of the Year. Available at: https:/www.cnet.com/news/2019-data-breach-hall-of-shame-these-were-thebiggest-data-breaches-of-the-year/

Howe, A. (2020, April 16). Courtroom Access: Faced with a Pandemic, the Supreme Court Pivots. Available at: https://www.scotusblog.com/2020/04/courtroom-access-faced-with-a-pandemic-the-supreme-courtpivots/

Hurley, L., \& Chung, A. (2020, April 13). A U.S. Supreme Court First: Arguments by Teleconference Including Major One Involving Trump. Available at: https:/www.reuters.com/article/us-usa-court-trumpfinances/u-s-supreme-court-to-hear-cases-by-teleconference-including-major-one-involving-trumpidUSKCN21V1D4

Jang-Jaccard, J., \& Nepal, S. (2014). A survey of emerging threats in cybersecurity. Journal of Computer and System Sciences, 80(5), 973-993.

Justice Management Institute. (2020). Responses to COVID-19 by Criminal Justice Systems: Courts. Available at: http://www.jmijustice.org/covid-19/covid-19-courts/

Kaczynski, A., Steck E., \& McDermott, N. (2020, April 18). 'Nothing to Worry about' and 'It's Being Contained': How Trump Officials Downplayed the Coronavirus. Available at: https://www.cnn. com/2020/04/18/politics/kfile-trump-officials-coronavirus/index.html

Killian, L. M. (2002). An introduction to methodological problems of field studies in disasters. In R. A. Stallings (Ed.), Methods of disaster research (pp. 49-93). Bloomington, IN: Xlibris Corporation.

Lynch, M. J. (2016). The ecological distribution of community advantage and disadvantage: Power structures, political economy, communities, crime and justice. Critical Criminology, 24(2), 247-262.

McCormick, T., and Lufrano, R. (2020). Will virtual jury trials be part of the "new Normal" ushered in by the COVID-19 pandemic? The National Law Review, X (180).

McCrohan, K. F., Engel, K., \& Harvey, J. W. (2010). Influence of awareness and training on cyber security. Journal of Internet Commerce, 9(1), 23-41.

Miller, C. (2020, June 30). How COVID-19 Is Impacting California Courts: Roundup of Services. Available at: https://www.law.com/therecorder/2020/06/16/how-covid-19-is-impacting-california-courts-roundupof-services/?slreturn=20200528125509

National Association of Court Management. (2020a, April 2). The Coronavirus: How Are Courts Coping with the Crisis? Episode 1 (Audio Podcast). Available at: https://anchor.fm/courtleaderpodcast/episodes/TheCoronavirus-How-are-Courts-Coping-with-the-Crisis\%2D\%2DApril-2\%2D\%2D2020-Episode-ec8bfr

National Association of Court Management. (2020b, April 23). The Coronavirus: How Are Courts Coping with the Crisis? Episode 4 (Audio Podcast). Available at: https://anchor. $\mathrm{fm} /$ courtleaderpodcast/episodes/The-Coronavirus-How-are-Courts-Coping-with-the-Crisis\%2D\%2 DApril-2\%2D\%2D2020-Episode-ec8bfr.

National Association of Drug Court Professionals. (2018). Justice for All: National Drug Court Month (May 2018). Available at: https://www.nadcp.org/wp-content/uploads/2018/04/National-Drug-CourtMonth-Field-Kit-2018_final.pdf

National Center for State Courts. (2020, March 26). Prioritization of case types. Available at: https://www. ncsc.org/ /media/Files/PDF/Newsroom/Coronavirus\%20Resources/Pandemic-Prioritization-of-CaseTypes.ashx

National Center for State Courts. (2020, April 15). Lights, Camera, Motion!: Act II (Webinar). Available at: https://vimeo.com/408411009

National Center for State Courts. (2020, May 1a). Developing Plans for Resuming Court Operations (Webinar). Available at: https://vimeo.com/414071907 
National Center for State Courts. (2020, May 1b). Considerations in Resuming Court Operations, Version \#1. Available at: https://www.ncsc.org/_data/assets/pdf_file/0015/34314/Considerations-in-ResumingCourt-Operations.pdf

National Center for State Courts. (2020a). Joint Technology Committee Bulletin: Strategic Issues to Consider when Starting Virtual Hearings. Available at: https:/www.ncsc.org/ /media/Files/PDF/About\%20 Us/Committees/JTC/2020-04-07\%20QR\%20Virtual\%20hearings_final.ashx

National Center for State Courts. (2020b). Implementing Technology in the Time of Crisis. Available at: https:/www.ncsc.org/ /media/Files/PDF/Newsroom/Coronavirus\%20Resources/Tech-In-Crisis.ashx

National Center for State Courts. (2020c). Cyber Threats and Cyber Hygiene during the COVID-19 Pandemic Crisis. Available at: https://www.ncsc.org/ /media/Files/PDF/Newsroom/Coronavirus $\% 20$ Resources/Pandemic-Cybersecurity-Threats-Cyber-Hygiene.ashx.

National Judicial College. (2020, March 19). The Judge's Role in a Pandemic (Webinar).

Orange County Government Florida. 2020. First Appearance List. Available at: http://www.ocfl. net/JailInmateServices/FirstAppearanceList.aspx\#.XvULmkVKhPY

Pretrial Services Agency. (2013). Pretrial Services Agency for the District of Columbia Continuity of Operations Plan. Available at: https://www.psa.gov/sites/default/files/PSA\%27s\%20Continuity\%20 of\%20Operations\%20Plan\%20\%28COOP\%29\%2002052014.pdf

Resumption of Jury Trials Workgroup. 2020. Resuming Jury Trials in Washington State. Available at: http://www.courts.wa.gov/content/publicUpload/COVID19\%20Response/Resuming\%20Jury\%20 Trials\%20in\%20Washington\%20State.PDF

Reuters. (2020). Partly False Claim: Trump Fired Entire Pandemic Response Team in 2018. Available at: https://www.reuters.com/article/uk-factcheck-trump-fired-pandemic-team-idUSKBN21C32M

Richards, E. P. and Rathbun, K. C., The Role of Law Enforcement in Public Health Emergencies: Special Considerations for an All-Hazards Approach (July 31, 2006). Bureau of Justice Assistance, 2006. Available at SSRN: https://ssrn.com/abstract=1899248

Sink, J., \& Parker, M. (2020, March 9). Trump's coronavirus contradicted by his own experts. Available at: https://www.bloomberg.com/news/articles/2020-03-09/trump-s-coronavirus-claims-often-contradictedby-his-own-experts

Slayton, D., Sydow, N., Mcormack, B. M., Miskely, E., Grant, G. A., Jablonski, J. R., \& Barry, J. (2020, April 7). Lights, Camera, Motions (Webinar). Available at: https://vimeo.com/405221328

Sun, Y. (2020, May 14). Security flaws in adobe acrobat reader allow malicious program to gain root on macOS silently. Available at: https://rekken.github.io/2020/05/14/Security-Flaws-in-Adobe-AcrobatReader-Allow-Malicious-Program-to-Gain-Root-on-macOS-Silently/

Supreme Court of Florida. (2009, May 8). AOSC09-20 In Re: Response of the Florida State Courts System to Influenza A(H1N1). Available at: https://www.floridasupremecourt.org/content/download/240699 /2129025/AOSC09-20.pdf

The Telegraph. (2012, June 6). Apple drops virus immunity claim for macs. Available at: https://www. telegraph.co.uk/technology/apple/9355995/Apple-drops-virus-immunity-claim-for-Macs.html

Torres, E. (2020). A Timeline of Cuomo's and Trump's Responses to Coronavirus Outbreak. Available at: https://abcnews.go.com/US/timeline-cuomos-trumps-responses-coronavirus-outbreak/story?id=69914641

United States Court of Appeals for the District of Columbia Circuit. (2020, March 17). In re: Court Operations in Light of the COVID-19 Pandemic. Available at: https://www.cadc.uscourts.gov/intranet/home. nsf/Content/Announcement+-+Standing+Order+In+Re+Oral+Arguments+COVID-19 /\$FILE/COVIDStandingOrder.pdf

United States Department of Health and Human Services. (2012). An HHS Retrospective on the 2009 H1N1 Influenza Pandemic to Advance All Hazards Preparedness. Available at: https://www.phe. gov/Preparedness/mcm/h1n1-retrospective/Documents/h1n1-retrospective.pdf

Publisher's Note Springer Nature remains neutral with regard to jurisdictional claims in published maps and institutional affiliations. 
Julie Marie Baldwin PhD, is the Associate Director for Research for the Justice Programs Office at American University and a Scholar in Residence in the Department of Justice, Law \& Criminology at American University. She specializes in translational and evaluation research (with a focus on treatment courts and prevention and intervention programs), court operations, substance use and misuse, and subcultures including the military, law enforcement, and gangs. She serves a research partner for a variety of agencies and organizations and has had her research funded by NIJ, NSF, SAMHSA, BJA, and NIC, as well as local government entities.

John M. Eassey received his Ph.D. from the University of Florida and is currently a quantitative methodologist at American University. His research interests relate to crime across the life course, including the statistical methodology necessary to study such phenomenon. Within this domain, he specializes in crime and delinquency related to employment and employment conditions, substance use among general and special populations, and the relationship between peers and criminal behavior across the life course.

Erika J. Brooke $\mathrm{PhD}$, is a Lecturer in Criminology in the Department of Sociology and Criminology \& Law at the University of Florida. Her research interests revolve around the courts to corrections pipeline with special emphasis on the military service and crime relationship, problem solving courts, and substance use and abuse. Some of her recent work has been published in Crime \& Delinquency, Journal of Offender Rehabilitation, Corrections: Policy, Practice, and Research, and The Journal of Drug Issues. 